\title{
Reunião Anual do ChemPubSoc Europe, Lisboa, 20-21 de Abril
}

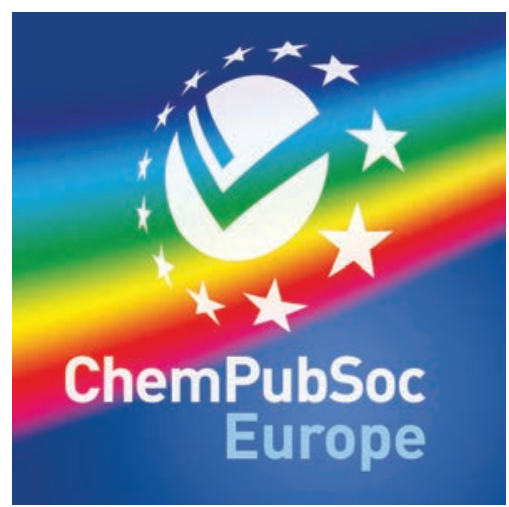

Em homenagem à SPQ pelo seu centenário, o consórcio editorial ChemPubSoc Europe (CPSE), que congrega 16 sociedades químicas europeias (de 15 países) e a editora Wiley-VCH, realizou desta vez a sua reunião anual em Lisboa. Para além do Presidente e da Vice-Presidente da SPQ, estiveram presentes representantes das sociedades de química da Alemanha, Áustria, Bélgica, Eslováquia, França, Holanda, Hungria, Itália, República Checa, Suécia e Suíça, e também da Wiley-VCH (incluindo os editores das revistas Angewandte Chemie e Chemistry - A European Journal), num total de 20 participantes. Por problemas de saúde de última hora, não participaram os representantes de Espanha e da Polónia. A Grécia não se faz representar há vários anos.

Foi, como sempre, dia e meio de trabalho intenso, mas com tempo para uma curta deslocação em fim de tarde ao Museu e Laboratorio Chimico da Escola Politecnica, onde houve uma visita guiada pela Dra Marta Lourenço, muito apreciada pelos participantes, e a que se seguiu um jantar no Terreiro do Paço, durante o qual o Prof. José Empis, que desempenhou várias funções na European Association for Chemical and Molecular Sciences (EuCheMS), incluindo a de tesoureiro, recebeu das mãos do Prof. Francesco de Angelis a medalha de honra daquela associação. Na mesma ocasião, o Prof. Wolfram Koch, Diretor Executivo da Sociedade Alemã de Química (Gesellschaft Deutscher Chemiker), entregou ao Presidente da SPQ uma missiva de felicitações da GDCh pelo centenário. Este recebeu também, da Wiley-VCH, na pessoa da Vice-Presidente e Diretora Executiva para a Química, Dra Eva Wille, quatro volumes contendo todos os artigos publicados por portugueses nas revistas do consórcio (cerca de 500), desde o início, em 1998. Estes representam 1,3\% do total dos artigos publicados no mesmo período nas revistas do consórcio (as percentagens oscilam entre $2,4 \%$ no
EurJIC e $0,51 \%$ no ChemSusChem). Como se vê no gráfico, a contribuição nacional tem vindo a aumentar, em termos absolutos, mas está muito abaixo do que poderia ser (o ISI registou, em 2011, cerca de 1600 publicações em Química de autores com endereço português).

Mário Berberan e Santos (berberan@ist.utl.pt) Presidente da SPQ

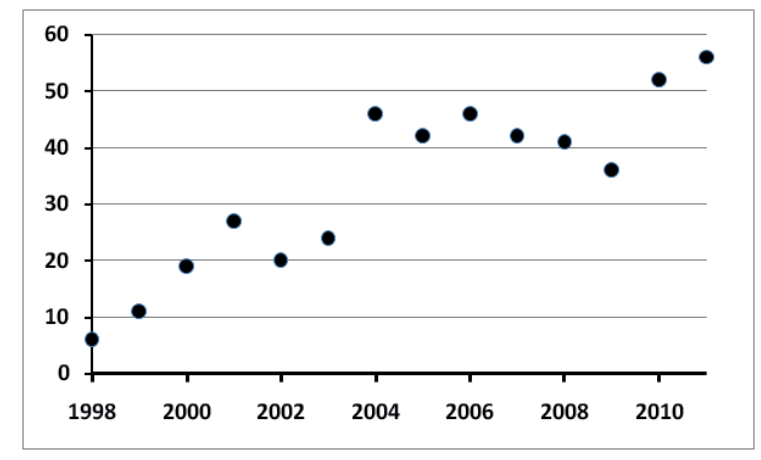

Publicações portuguesas em revistas CPSE

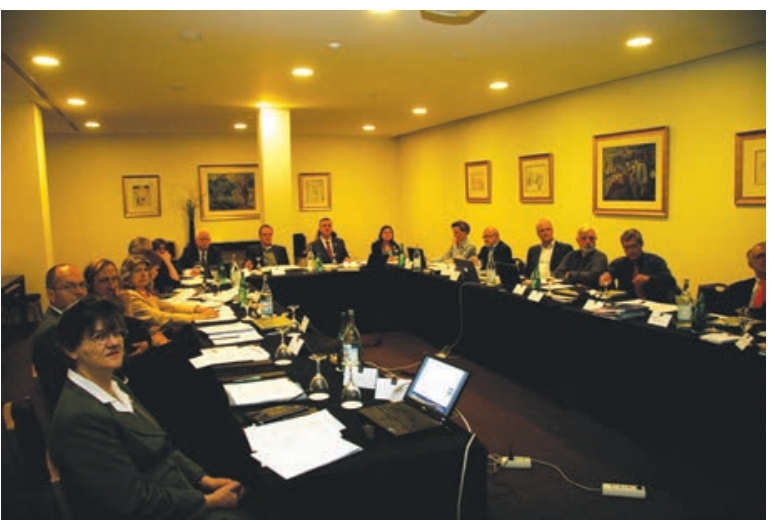

Aspeto dos trabalhos da reunião de Lisboa

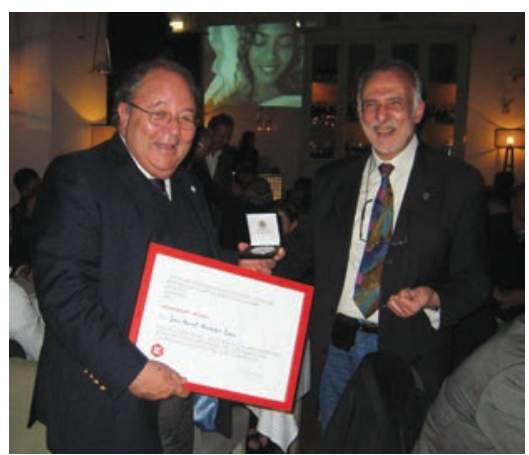

Francesco de Angelis entrega a José Empis o diploma e a medalha de honra da EuCheMS

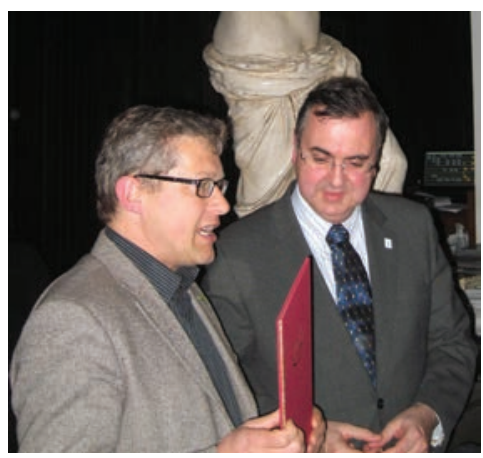

Wolfram Koch, diretor executivo da Sociedade Alemã de Química, entrega a Mário Berberan e Santos uma missiva de felicitações da GDCh pelo centenário da SPQ 


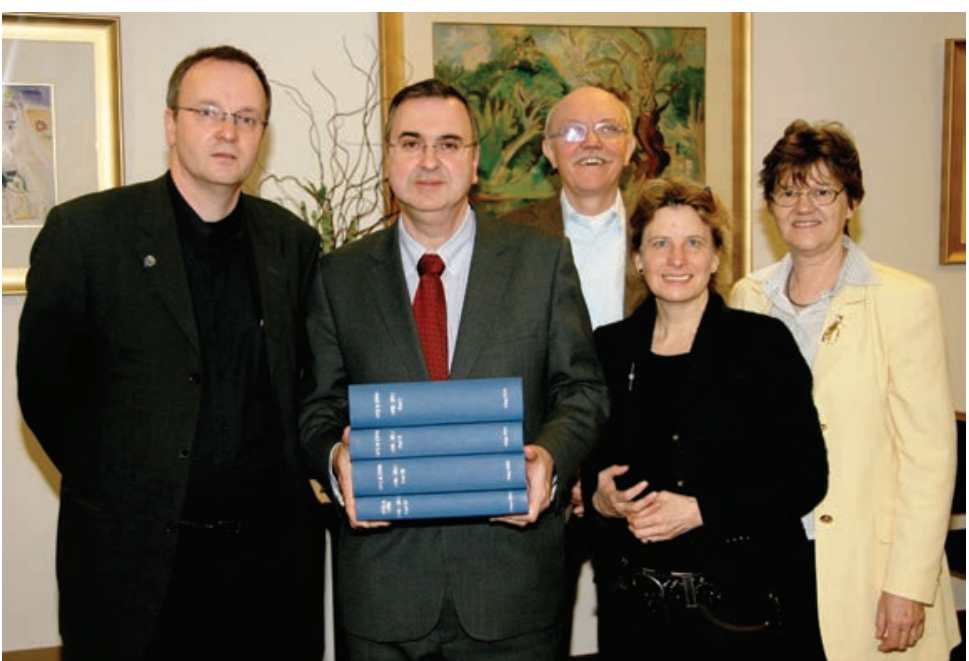

Foto em cima: o Presidente da SPQ, juntamente com os colegas da Wiley-VCH segurando quatro volumes com quase 500 artigos de autores nacionais. Da esquerda para a direita: Neville Compton (editor de Chemistry - A European Journal), Mário Berberan e Santos (SPQ), Peter Goelitz (Vice-Presidente e Diretor de Publicações, Editor de Angewandte Chemie), Eva Wille (Vice-Presidente e diretora Executiva para a Química) e Karen Hindson (Editora Coordenadora do CPSE). Imagem à direita: primeira página do primeiro volume

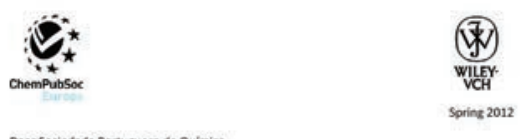

Dear Sociedade Portuguess de Quimica,

Many coneratulations on the " 1000 Anos" of vour society from the Efitionia Ofhees of Wiley-VCH, Chemistry yournals. We would dike to take this opsortunity to thank you and all the society

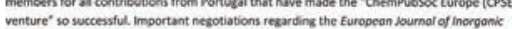

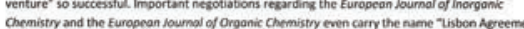
Th has atrays been a pleasure and very stimulating to woek with your society and theit representa.

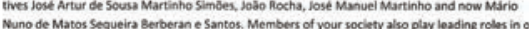

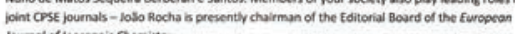
soumel of hargonic Chemistry

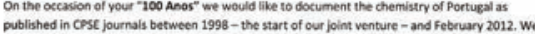

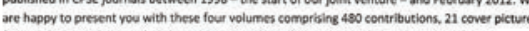
ment socumented here

We look formard to continuing the journer togecther in chemistry and publishing and wish you all the best for the future.

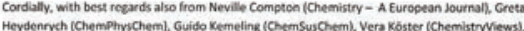

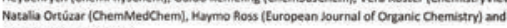

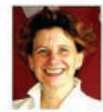

$\varepsilon x$

Evac, walle

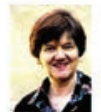

Kars

Karen Hindson
Cocedinsting Edition
CPSE loumnals

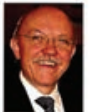

P

Peter Gostan

\section{Uma Molécula Chamada SPQ}

Num universo de algumas dezenas de milhões de moléculas conhecidas, era de esperar que existisse uma, cuja designação comum através de uma sigla de 3 letras fosse SPQ. E assim acontece realmente desde 1982, graças a Wolfbeis e a Urbano (veja-se Bregestovski, Waseem e Mukhtarov, Genetically encoded optical sensors for monitoring of intracellular chloride and chloride-selective channel activity, Frontiers in Molecular Neuroscience 2 (2009) 1, e referências aí citadas), como descobriu há pouco, por acaso, a Sociedade Portuguesa de Química. Trata-se do 6-metoxi-N-(3-sulfonatopropil)quinolínio, ou SPQ, molécula usada como sensor fluorescente de halogenetos (cloreto, brometo e iodeto), o que quer a Divisão de Química<smiles>COc1ccc2c(ccc[n+]2CCCS(=O)(=O)[O-])c1</smiles>

Analítica, quer o Grupo de Fotoquímica, verão certamente com bons olhos.

Como é uma molécula orgânica usada para medir concentrações de iões inorgânicos em meios biológicos por um método espectroscópico, também é certamente relevante para as Divisões de Química Orgânica, Inorgânica, Química-Física e de Ciências da Vida.

Por coincidência, a emissão de fluorescência desta molécula dá-se no azul (máximo a $450 \mathrm{~nm}$ ), que é, como se sabe, a cor da SPQ. Talvez o leitor conheça outras moléculas com nomes comuns curiosos que queira partilhar.

Sem entrar em pormenores, a SPQ verificou, por exemplo, que há moléculas cujas siglas coincidem com as de partidos políticos nacionais, clubes de futebol, etc.

Quanto a estes últimos, e pelo menos num caso, cuja identificação se deixa como passatempo aos respectivos aficionados, trata-se mesmo da fórmula de uma molécula triatómica!

Mário Berberan e Santos (berberan@ist.utl.pt)

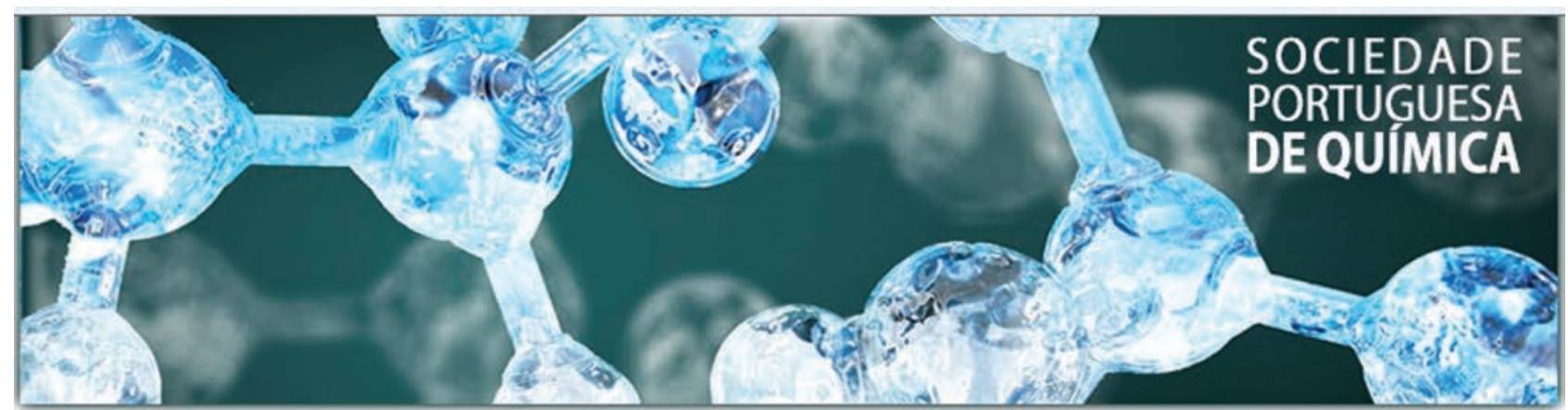

